\title{
Hubungan Dukungan Sosial Keluarga dengan Stres Kerja pada Petani Tembakau di Kecamatan Kalisat Kabupaten Jember
}

\section{(Relation of Social Family Support with Job Stress on Tobacco Farmers in Kalisat District, Jember Regency)}

\author{
Sindy Arie Pradini, Emi Wuri Wuryaningsih, Enggal Hadi \\ Kurniyawan Fakultas Keperawatan Universitas Jember \\ Jl. Kalimantan No. 37 Kampus Tegal Boto, Jember Telp./Fax. \\ (0331) 323450 email: emiwuryaningsih.unej@gmail.com
}

\begin{abstract}
Job stress can result in an imbalance in the psychological and physical condition of a worker. Job stress on farmers can occur due to heavy work, long working hours, exposure of farmers to pesticides and nicotine. Farmers who have the risk of job stress will need support from the family. The purpose of this study was to determine the relationship between family social support and job stress on tobacco farmers in Kalisat District, Jember Regency. This study uses a cross-sectional design with sampling techniques using cluster sampling and proportional sampling with a sample size of 91 (Cl: 90\%). The measuring instruments used were job stress and family support questionnaires (Cronbach's Alpha 0.937; 0.793). This research has been declared to have passed the health research ethics feasibility test. The results of this study indicate that the job stress experienced by farmers obtains the results of the middle score of 47(45-49) included in the low category, while the family social support is obtained in the middle value 75(73-76) include in the very high category. The results of the analysis using the Spearman test obtained a $p$-value of 0.174 ( $p>0.05$ ), there was no relationship between family social support and work stress on tobacco farmers in Kalisat District, Jember Regency. There's no relationship between this research and bivariate analysis, but the results of the analysis of the two variables are in accordance with the theory, if family social support is high, then work stress is low.
\end{abstract}

Keywords: Social Family Support, Job Stress, Tobacco Farmers

\begin{abstract}
Abstrak
Stres kerja dapat mengakibatkan adanya ketidakseimbangan kondisi psikis serta fisik seorang pekerja. Stres kerja pada petani dapat terjadi karena pekerjaan berat, lama waktu bekerja, terpaparnya petani dengan pestisida dan nikotin. Petani yang memiliki risiko mengalami stres kerja akan membutuhkan dukungan dari keluarga. Tujuan dari penelitian ini untuk mengetahui hubungan antara dukungan sosial keluarga dengan stres kerja pada petani tembakau di Kecamatan Kalisat Kabupaten Jember. Penelitian ini menggunakan desain cross- sectional dengan teknik pengambilan sampel menggunakan cluster sampling dan proportional sampling dengan besar sampel $91(\mathrm{Cl}=90 \%)$. Alat ukur yang digunakan yaitu kuesioner stres kerja dan dukungan keluarga (Cronbach's Alpha 0,937; 0,793). Penelitian ini telah dinyatakan lulus uji kelaikan etik penelitian kesehatan. Hasil penelitian ini menunjukkan bahwa stres kerja yang dialami oleh petani memperoleh hasil nilai tengah 47(45-49) yang termasuk dalam kategori rendah, sedangkan dukungan sosial keluarga diperoleh nilai tengah 75(73-76) yang termasuk dalam kategori sangat tinggi. Hasil analisis dengan uji Spearman didapatkan nilai $p$-value sebesar 0,174 $(p>0,05)$ yaitu tidak ada hubungan antara dukungan sosial keluarga dengan stres kerja pada petani tembakau di Kecamatan Kalisat Kabupaten Jember. Penelitian ini secara analisis bivariat tidak terdapat hubungan, tetapi hasil analisis kedua variabel sesuai dengan teori yaitu apabila dukungan sosial keluarga tinggi, maka stres kerja rendah.
\end{abstract}

Kata Kunci: Dukungan Sosial Keluarga, Stres Kerja, Petani Tembakau 


\section{Pendahuluan}

Indonesia menempati peringkat kelima di dunia penghasil tembakau terbesar yaitu sebesar 226.704 ton pada tahun 2011 [1]. Data yang didapatkan melalui Komunitas Kretek pada tahun 2015, jumlah keseluruhan petani tembakau di Indonesia sebanyak 527.688 orang, di Jawa Timur terdapat 301.847 orang yang merupakan daerah penghasil tembakau terbanyak di Indonesia. Indonesia termasuk dalam tujuh negara penghasil daun tembakau di dunia yang melibatkan banyak petani baik sebagai penanam penuh waktu ataupun paruh waktu [2].

Pada tahun 2015 sampai 2017, tanaman tembakau yang ditanam atau diproduksi di perkebunan rakyat setiap tahun mengalami peningkatan [3]. Banyaknnya lahan pertanian yang didominasi oleh tanaman tembakau, tentunya juga banyak permasalahan yang dihadapi oleh petani terkait lahan pertanian yang sedang dikelola. Ada beberapa hal yang menjadi permasalahan bagi petani, diantaranya yaitu perubahan cuaca, perubahan harga, hama tanaman, turunnya pembelian, adanya modal usaha yang besar, lama waktu bekerja, terpaparnya petani dengan pestisida dan nikotin, serta petani berisiko mengalami masalah kesehatan akibat terpapar tembakau setiap hari. Beberapa permasalahan tersebut dapat menimbulkan risiko terjadinya stres pada petani.

Stres merupakan suatu perasaan ragu terhadap kemampuan diri sendiri untuk mengatasi suatu hal yang sedang dialaminya [4]. Stres dapat terjadi akibat adanya stresor. Seseorang terkadang merasa tidak mampu, tidak nyaman, bosan, bahkan dapat merasa tertekan dalam melakukan pekerjaan. Seseorang yang mengalami gejala tersebut sebenarnya sedang mengalami stres kerja.

Stres kerja merupakan suatu keadaan ketegangan yang menciptakan adanya ketidakseimbangan psikis serta fisik yang mempengaruhi proses berfikir, emosi, dan kondisi seorang pekerja. Stres kerja juga dapat diartikan dengan stres psikologis dengan semua jenis kekuatan fisik, mental, sosial serta tekanan yang dihasilkan dalam melakukan pekerjaan [5].

Setiap orang dapat mengalami stres yang dapat mengganggu kehidupan sehari-hari, termasuk dalam melakukan pekerjaan [6]. Stres kerja salah satunya dapat dipengaruhi oleh dukungan sosial [7]. Dukungan sosial merupakan fungsi dari ungkapan perilaku suportif yang diberikan oleh orang yang dianggap bermakna bagi individu yang menerimanya [8].

Dukungan sosial juga merupakan bentuk pemberian perasaan nyaman secara psikologis maupun fisik saat seseorang mendapatkan berbagai tekanan. Petani yang mengalami tekanan akibat pekerjaan dan memiliki dukungan sosial yang rendah akan menyebabkan petani mengalami ketegangan dalam pekerjaan, stres, masalah kesehatan mental serta depresi [9].

Berdasarkan studi pendahuluan yang dilakukan, Kecamatan Kalisat memiliki 12 desa dengan jumlah masyarakat yang bekerja pada sektor pertanian berjumlah 20.040 jiwa dan populasi petani tembakau tidak diketahui jumlahnya. Masyarakat mayoritas bekerja sebagai petani tembakau saat musim tembakau. Tanaman tembakau hanya ditanam saat musim kemarau.

Berdasarkan latar belakang tersebut, maka peneliti tertarik untuk mengetahui apakah ada hubungan antara dukungan sosial keluarga dengan stres kerja pada petani tembakau di Kecamatan Kalisat Kabupaten Jember.

\section{Metode Penelitian}

Penelitian ini termasuk dalam jenis penelitian korelasional dengan pendekatan cross- sectional. Populasi dalam penelitian ini adalah semua masyarakat yang bekerja sebagai petani tembakau yang jumlahnya tidak diketahui, yang terdapat pada 6 desa di Kecamatan Kalisat yaitu Desa Gambiran, Desa Patempuran, Desa Plalangan, Desa Sukoreno, Desa Sumberkalong dan Desa Sumberketempa. Teknik sampling menggunakan teknik cluster sampling dan proportional sampling yaitu dengan jumlah sampel 91 responden dengan kriteria inklusi yaitu bekerja sebagai petani tembakau penuh waktu, bekerja pada lahan milik orang lain (buruh petani tembakau), tinggal dengan keluarga dan bersedia menjadi responden.

Alat pengumpulan data menggunakan kuesioner stres kerja yang telah dilakukan uji reliabilitas dengan Cronbach's Alpha 0,973 yang terdiri dari 18 pertanyaan dan kuesioner dukungan keluarga dengan Cronbach's Alpha 0,793 yang terdiri dari 24 pertanyaan, kedua kuesioner menggunakan skala likert. Data dianalisis menggunakan uji Spearman untuk mengetahui hubungan dua variabel. Data penelitian diambil dengan menghormati harkat dan martabat subjek penelitian menggunakan lembar persetujuan penelitian (informed consent), lulus uji kelaikan etik penelitian kesehatan oleh 
Komite Etik Penelitian Kesehatan (KEPK) dari Fakultas Kedokteran Gigi (FKG) Universitas Jember dengan nomor sertifikat uji etik No. 311/UN25.8/KEPK/DL/2019, menghormati privasi atau kerahasiaan responden, memperhatikan keadilan serta kemanfaatan terhadap responden. Hipotesis dalam penelitian ini yaitu Ha diterima yang artinya ada hubungan antara dukungan sosial terhadap stres kerja pada petani tembakau di Kecamatan Kalisat. Ha diterima apabila $p$ value $<0,05$.

\section{Hasil Penelitian \\ Karakteristik Responden}

Tabel 1. Distribusi Karakteristik Responden pada Petani Tembakau di Kecamatan Kalisat Kabupaten Jember (Februari 2019, $\mathrm{n}=91$ )

\begin{tabular}{|c|c|c|}
\hline $\begin{array}{l}\text { Karakterisrik } \\
\text { Responden }\end{array}$ & Frekuensi & $\begin{array}{c}\text { Persentas } \\
\text { e } \\
(\%)\end{array}$ \\
\hline $\begin{array}{c}\text { Umur (Tahun) } \\
\text { Mean } \pm S D\end{array}$ & \multirow[t]{2}{*}{91} & \multirow{2}{*}{$\begin{array}{l}45,45 \\
\pm 11,880\end{array}$} \\
\hline Jenis Kelamin & & \\
\hline $\begin{array}{l}\text { Laki-laki } \\
\text { Perempuan }\end{array}$ & $\begin{array}{l}47 \\
44\end{array}$ & $\begin{array}{l}51,6 \\
48,4\end{array}$ \\
\hline Pendidikan & & \\
\hline $\begin{array}{l}\text { SD/Tidak } \\
\text { sekolah }\end{array}$ & 62 & 68,1 \\
\hline $\begin{array}{l}\text { SMP/MTs } \\
\text { SMA//MAN }\end{array}$ & $\begin{array}{l}12 \\
17\end{array}$ & $\begin{array}{l}13,2 \\
18,7\end{array}$ \\
\hline \multicolumn{3}{|l|}{ Penqhasilan } \\
\hline $\begin{array}{l}<2.000 .000 \\
>2.000 .000\end{array}$ & $\begin{array}{l}74 \\
17\end{array}$ & $\begin{array}{l}81,3 \\
18,7\end{array}$ \\
\hline \multicolumn{3}{|l|}{$\begin{array}{l}\text { Peran dalam } \\
\text { Keluarqa }\end{array}$} \\
\hline $\begin{array}{l}\text { Kepala } \\
\text { keluarga }\end{array}$ & 44 & 48,4 \\
\hline $\begin{array}{l}\text { Istri } \\
\text { Anak }\end{array}$ & $\begin{array}{c}44 \\
3\end{array}$ & $\begin{array}{c}48,4 \\
3,3\end{array}$ \\
\hline \multicolumn{3}{|l|}{$\begin{array}{l}\text { Jumlah } \\
\text { Anggota } \\
\text { Keluarqa }\end{array}$} \\
\hline $\begin{array}{l}\leq 4 \text { orang } \\
>4 \text { orang }\end{array}$ & $\begin{array}{l}71 \\
20\end{array}$ & $\begin{array}{l}78,0 \\
22,0\end{array}$ \\
\hline \multicolumn{3}{|c|}{$\begin{array}{l}\text { *SD=Standar Deviasi } \\
\text { Sumber: Data Primer, Februari } 2019\end{array}$} \\
\hline $\begin{array}{l}\text { Dukungan Sosial } \\
\text { Tabel 2. Distribusi } \\
\text { Dukunga } \\
\text { Petani } \\
\text { Kalisat } \\
2019, n=\end{array}$ & $\begin{array}{l}\text { Keluarga } \\
\text { esponden M } \\
\text { Sosial K } \\
\text { embakau } \\
\text { abupaten Je } \\
\text { 1) }\end{array}$ & $\begin{array}{l}\text { Menurut Indikator } \\
\text { Keluarga pada } \\
\text { di Kecamatan } \\
\text { ember (Februari }\end{array}$ \\
\hline
\end{tabular}

\begin{tabular}{lcc}
\hline \multicolumn{1}{c}{$\begin{array}{c}\text { Variabel Indikator } \\
\text { Dukungan Sosial } \\
\text { Keluarga }\end{array}$} & Mean & $\begin{array}{c}\text { Standar } \\
\text { Deviasi }\end{array}$ \\
\hline Dukungan Emosional & 18,96 & $\pm 0,893$ \\
Dukungan Instrumental & 20,43 & $\pm 1,275$ \\
Dukungan Informasi & 18,34 & $\pm 0,957$ \\
Dukungan Penghargaan & 16,86 & $\pm 0,659$ \\
\hline
\end{tabular}

Sumber: Data Primer, Februari 2019

Tabel 3. Distribusi Responden Menurut Dukungan Sosial Keluarga pada Petani Tembakau di Kecamatan Kalisat Kabupaten Jember (Februari 2019, n=91)

\begin{tabular}{lc}
\hline \multicolumn{1}{c}{ Variabel } & Median $\left(\mathbf{P}_{25}-\mathbf{P}_{75}\right)$ \\
\hline $\begin{array}{l}\text { Dukungan Sosial } \\
\text { Keluarga }\end{array}$ & $75,00(73,00-76,00)$ \\
\hline
\end{tabular}

Sumber: Data Primer, Februari 2019

\section{Stres Kerja}

Tabel 4. Distribusi Responden Menurut Indikator Stres Kerja pada Petani Tembakau di Kecamatan Kalisat Kabupaten Jember (Februari 2019, $\mathrm{n}=91$ )

\begin{tabular}{lcc}
\hline \multicolumn{1}{c}{$\begin{array}{c}\text { Variabel Indikator } \\
\text { Stres Kerja }\end{array}$} & Mean & $\begin{array}{c}\text { Standar } \\
\text { Deviasi }\end{array}$ \\
\hline Gejala Fisiologis & 20,43 & $\pm 2,522$ \\
Gejala Psikologis & 14,91 & $\pm 1,768$ \\
Gejala Perilaku & 11,85 & $\pm 1,219$ \\
\hline
\end{tabular}

Sumber: Data Primer, Februari 2019

Tabel 5. Distribusi Responden Menurut Stres Kerja Pada Petani Tembakau di Kecamatan Kalisat Kabupaten Jember (Februari 2019, $\mathrm{n}=91$ )

\begin{tabular}{cc}
\hline Variabel & Median $\left(\mathbf{P}_{\mathbf{2 5}}-\mathbf{P}_{\mathbf{7 5}}\right)$ \\
\hline Stres Kerja & $47,00(45,00-49,00)$ \\
\hline Sumber: Data Primer, Februari 2019
\end{tabular}

\section{Dukungan Sosial Keluarga dengan Stres Kerja}

Tabel 6. Hubungan Dukungan Sosial Keluarga dengan Stres Kerja Pada Petani Tembakau di Kecamatan Kalisat Kabupaten Jember (Februari 2019, $\mathrm{n}=91$ )

\begin{tabular}{|c|c|c|}
\hline \multicolumn{3}{|c|}{ Dukungan Sosial Keluarga } \\
\hline & $\mathbf{R}$ & $p$-value \\
\hline Stres Kerja & 0,144 & 0,174 \\
\hline
\end{tabular}

Sumber: Data Primer, Februari 2019 


\section{Pembahasan}

\section{Karakteristik Responden}

Rata-rata umur petani tembakau di Kecamatan Kalisat adalah 45 tahun. Hal ini sesuai dengan analisis kebijakan pertanian Indonesia yaitu petani sebagian besar memiliki umur pada kisaran 45-54 tahun yang merupakan ujung usia produktif [10]. Semakin bertambah usia maka individu akan semakin bersikap positif dalam melaksanakan suatu pekerjaan seperti perilaku, pengalaman, serta komitmen untuk menjaga kualitas kerjanya [11].

Petani tembakau lebih banyak yang berjenis kelamin laki $(51,6 \%)$ yaitu sebanyak 47 orang. Banyaknya laki-laki yang bekerja disebabkan karena pengambilan keputusan yang berkaitan dengan aktivitas produktif didominasi oleh lakilaki [12].

Tingkat pendidikan responden sebagian besar diperoleh petani tembakau dengan pendidikan terakhir Sekolah Dasar (SD) dan tidak bersekolah yaitu sebanyak 62 orang $(68,1 \%)$. Pendidikan dapat menggambarkan tingkat pengetahuan dan kemampuan petani dalam segala hal, seperti peningkatan pengetahuan, keterampilan, serta perubahan sikap pada petani [13]. Peneliti berasumsi bahwa tingkat pendidikan belum sepenuhnya dapat mempengaruhi stres kerja pada petani tembakau karena terdapat faktor-faktor lain seperti usia, pengalaman, serta beban tanggungan keluarga yang dapat berpengaruh terhadap stres kerja pada petani tembakau.

Mayoritas petani tembakau memiliki penghasilan perbulan dibawah Rp. 2.000.000, yaitu sebanyak 74 orang $(81,3 \%)$. Penghasilan petani per tahun termasuk dalam kategori yang sangat rendah [14]. Penghasilan yang didapatkan oleh petani digunakan sebagai indikator penting, karena penghasilan tersebut merupakan sumber utama dalam mencukupi kebutuhan sehari-hari pada petani. Tuntutan pemenuhan kebutuhan tentunya membuat petani harus bekerja dengan giat, kebutuhan ekonomi juga mempengaruhi aspek kehidupan petani termasuk tingkat penghasilan petani [15]. Peneliti berasumsi bahwa tingkat penghasilan yang diperoleh oleh petani dapat mempengaruhi stres kerja pada petani tembakau karena para petani harus bekerja untuk memenuhi kebutuhan ekonomi keluarganya.

Sebagian besar petani tembakau di Kecamatan Kalisat memiliki anggota keluarga kurang dari atau sama dengan 4 orang yang tinggal bersama, yaitu sebanyak 71 petani tembakau $(78,0 \%)$. Rata-rata petani memiliki jumlah anggota keluarga sebanyak 4 orang. Jumlah anggota keluarga berpengaruh terhadap jumlah tanggungan keluarga. Jumlah tanggungan keluarga yang besar dapat menjadi salah satu faktor petani harus bekerja lebih giat lagi, apalagi jika anggota keluarga masih berusia non-produktif [16]. Jumlah anggota keluarga juga berpengaruh terhadap pemberian dukungan kepada petani tembakau, karena dukungan keluarga dapat berupa melakukan aktivitas bersama untuk pengalihan masalah dan untuk mengurangi stres [17].

\section{Dukungan Sosial Keluarga pada Petani Tembakau di Kecamatan Kalisat Kabupaten Jember}

Hasil analisis univariat menunjukkan bahwa hasil rata-rata dukungan sosial keluarga pada petani tembakau di Kecamatan Kalisat memperoleh nilai 75 dari nilai minimal 18 dan nilai maksimal 90. Nilai rata-rata tersebut termasuk dalam kategori sangat tinggi. Pada penjabaran indikator dukungan sosial keluarga, didapatkan hasil bahwa responden lebih banyak mendapatkan dukungan instrumental dari keluarga. Bentuk dari dukungan instrumental dapat mengurangi kecemasan, beban pekerjaan, serta meringankan semua pekerjaan yang dihadapi sehingga petani tembakau tidak merasa tertekan saat mengalami stres kerja.

Petani mendapatkan dukungan lingkungan sosial budaya yang termasuk dalam kategori rendah [18]. Dukungan tersebut terdiri dari dukungan kearifan lokal, dukungan tokoh masyarakat serta dukungan kelompok tani. Dukungan sosial keluarga dapat berupa interaksi dan dukungan sosial yang berlangsung dalam lingkup internal, seperti dukungan yang diperoleh dari suami, istri, anak, saudara kandung, orang tua, serta anggota keluarga lainnya [19]. Adanya dukungan sosial keluarga dapat menghasilkan solusi yang lebih baik untuk masalah yang terjadi dalam pekerjaan, serta membuat pekerjaan yang dilakukan menjadi lebih produktif dan menyenangkan [20].

Pada penelitian yang telah dilakukan, sebagian besar petani tembakau mendapatkan dukungan sosial keluarga yang termasuk dalam kategori sangat tinggi. Hal ini disebabkan oleh tugas keluarga yaitu memberikan motivasi kepada anggota keluarga lain, baik dalam keadaan suka maupun duka. Petani tembakau mendapatkan dukungan dari keluarga terhadap pekerjaan yang dilakukan. Dukungan tersebut dapat berpengaruh terhadap kinerja petani 
tembakau dalam melakukan pekerjaan. Semakin tinggi dukungan yang diberikan oleh keluarga, maka semangat petani tembakau untuk bekerja juga akan meningkat.

\section{Stres Kerja pada Petani Tembakau di Kecamatan Kalisat Kabupaten Jember}

Hasil analisis univariat menunjukkan bahwa hasil rata-rata stres kerja pada petani tembakau di Kecamatan Kalisat memperoleh nilai 47 dari nilai minimal 24 dan nilai maksimal 96. Nilai rata-rata tersebut termasuk dalam kategori rendah. Hal ini membuktikan bahwa kemampuan koping pada petani tembakau cukup baik. Pada penjabaran indikator stres kerja, petani tembakau sebagian besar mengalami stres kerja dengan gejala fisiologis. Gejala fisiologis yang sering dialami oleh responden meliputi sakit kepala, gangguan pada perut, gangguan pernafasan serta kelelahan fisik.

Petani yang mengalami stres sebagian besar termasuk dalam kategori stres berat dan sisanya mengalami stres ringan [21]. Stres merupakan gangguan yang menyebabkan tekanan dan ketegangan tidak menyenangkan yang berasal dari luar diri individu [22]. Stres kerja juga dapat dikatakan sebagai stres psikologis dengan semua jenis kekuatan fisik, mental, sosial serta tekanan yang dihasilkan dalam melakukan pekerjaan [5].

Pada penelitian yang telah dilakukan, sebagian besar petani tembakau mengalami stres kerja yang termasuk dalam kategori rendah. Hal ini dapat dipengaruhi oleh beberapa faktor, salah satunya yaitu pengalaman. Petani tembakau menyatakan bahwa semakin lama masa kerja yang telah dilewati maka semakin terbiasa petani tersebut terhadap faktor-faktor yang mungkin akan menyebabkan stres kerja. Pada penelitian ini, para petani tembakau ratarata sudah berada pada ujung usia produktif yang artinya petani tersebut telah lama melakukan pekerjaan sebagai petani.

\section{Hubungan Dukungan Sosial Keluarga dengan Stres Kerja pada Petani Tembakau di Kecamatan Kalisat Kabupaten Jember}

Penelitian ini mendapatkan hasil analisis yaitu tidak adanya hubungan antara dukungan sosial keluarga dengan stres kerja pada petani tembakau di Kecamatan Kalisat Kabupaten Jember. Penelitian serupa dilakukan oleh Berk, et al. (2012) tentang peran buffering dari dukungan sosial pada hubungan antara stres kerja dan niat untuk pergi yang diteliti dari karyawan pabrik di semua sektor. Penelitian tersebut menyatakan bahwa tidak ada hubungan yang signifikan mengenai hubungan sosial dengan stres akibat kerja [23].

Stres kerja dapat dipengaruhi oleh beberapa faktor, diantaranya yaitu tuntutan pekerjaan, jenis pekerjaan yang bersifat stres serta tanggungjawab untuk melakukan pekerjaan [24]. Stres kerja dapat dialami oleh siapa saja, termasuk petani tembakau. Petani yang tidak mengalami stres kerja akan lebih rendah untuk mengalami sakit [25]. Stres kerja dapat dipengaruhi oleh dukungan sosial [7]. Dukungan sosial keluarga akan membantu dalam mengurangi stres dan sangat penting untuk menjaga kesehatan mental individu [26]. Petani yang mengalami tekanan akibat pekerjaan dan memiliki dukungan sosial yang rendah akan menyebabkan petani mengalami ketegangan dalam pekerjaan, stres, masalah kesehatan mental [9].

Hasil penelitian yang didapatkan secara analisis bivariat tidak sesuai dengan teori. Pada hasil penelitian didapatkan dukungan sosial keluarga kurang berdampak terhadap stres kerja pada petani tembakau. Menurut peneliti, hal tersebut disebabkan oleh petani yang sudah terbiasa bekerja di sawah dalam masa waktu yang cukup lama sehingga stres kerja yang dialami oleh petani tembakau juga rendah. Petani tembakau sebagian besar tidak menunjukkan gejala stres saat proses penelitian, petani tembakau mengatakan bahwa mereka merasa senang bekerja sebagai petani karena pekerjaan tersebut telah menjadi pekerjaan mereka sejak lama.

Petani tembakau merupakan pekerjaan musiman yang dilakukan oleh petani yang bekerja pada lahan milik orang lain, apabila musim tembakau maka petani bekerja sebagai petani tembakau, sedangkan jika sudah tidak musim tembakau maka petani akan bekerja pada lahan milik orang lain yang sedang menanam padi, jagung, ataupun tanaman hortikultura. Pada analisis data yang dilakukan pada karakteristik responden dan stres kerja, diketahui ada beberapa karakteristik responden yang memiliki hubungan dengan stres kerja, diantaranya yaitu tingkat pendidikan dan peran dalam keluarga. Semakin rendah tingkat pendidikan maka akan semakin berisiko mengalami stres. Peran dalam keluarga juga dapat mempengaruhi stres karena berkaitan dengan beban tanggungan keluarga yang harus dipenuhi oleh kepala keluarga.

Dukungan yang diberikan oleh keluarga 
memang dapat dikatakan sangat baik terhadap petani tembakau, tetapi dukungan tersebut tidak begitu berpengaruh terhadap apa yang dialami petani tembakau selama melakukan pekerjaan di sawah. Dukungan sosial keluarga diberikan tidak hanya untuk mendukung pekerjaan petani tembakau tetapi juga diberikan pada saat anggota keluarga mempunyai masalah didalam ataupun diluar lingkup keluarga. Dukungan sosial keluarga yang tinggi dapat berpengaruh terhadap beberapa petani tembakau yang berisiko mengalami stres kerja karena tingkat stres kerjanya berada dalam kategori sedang.

\section{Simpulan dan Saran Simpulan}

Pada penelitian ini dapat diketahui bahwa tidak ada hubungan yang signifikan antara dukungan sosial keluarga dengan stres kerja pada petani tembakau di Kecamatan Kalisat Kabupaten Jember. Penelitian ini secara analisis bivariat tidak menunjukkan adanya hubungan, tetapi hasil analisis univariat menunjukkan bahwa dukungan sosial keluarga yang didapatkan oleh petani tembakau sangat tinggi dan stres kerja yang dialami oleh petani tembakau termasuk dalam stres kerja rendah.

\section{Saran}

Penelitian ini diharapkan dapat menjadi suatu referensi dalam mengadakan penelitian lebih lanjut mengenai faktor-faktor lain yang menyebabkan stres kerja pada petani tembakau. Selain itu, diharapkan peneliti untuk meningkatkan Confidence Interval $(\mathrm{Cl})$ atau derajat presisi menjadi 95\% pada penelitian selanjutnya.

\section{Daftar Pustaka}

[1] Tobacco Control Support Center (TCSC). Fakta Tembakau dan Permasalahannya di Indonesia. Ikatan Ahli Kesehatan Masyarakat Indonesia (IAKMI); 2014 [update 2016 Jun; cited 2018 Oct 15].

[2] Ahsan, A., Fajri, P.A., Nuzul, B., Wiyono, N.H., \& Widodo, P.T. Kondisi Petani Tembakau di Indonesia. Jakarta: Tobacco Control Support Center (TCSC)-Ikatan Ahli Kesehatan Masyarakat Indonesia (IAKMI); 2008 [update 2008 Okt 1;cited 2018 Oct 16].

[3] Kementerian Pertanian. Statistik Perkebunan Indonesia (Tree Crop Estate Statistics of Indonesia). Jakarta: Sekretariat
Direktorat Jendral Perkebunan; 2017 [cited 2018 Oct 19].

[4] Saam, Z., \& Wahyuni, S. Psikologi Keperawatan. Jakarta: Rajawali Pers; 2012.

[5] Khalatbari, J., Ghorbanshiroudi, S., \& Firouzbakhsh, M. Correlation of Job Stress, Job Satisfacation, Job Motivation and Burnout and Feeling Stress. Procedia Social and Behavioral Sciences [Internet]. 2013 Jun [cited 2018 Oct 18]: 860-863.

[6] Videbeck, S.L. Psychiatric-Mental Health Nursing. Fifth edition.Wolters Kluwe Health. Lippincott Wiliams \& Wilkins; 2011.

[7] Ramesh, A.S., \& Madhavi, C. Occupational Stress Among Farming People. The Journal of Agricultural Science [Internet]. 2009 Sep [cited 2018 Oct 21]:4 (3), 115-125.

[8] Saragih, S. A. Hubungan antara SelfEfficacy dan Dukungan Sosial dengan Coping Stress pada Petani Hortikultura dalam Mengelola Usaha Tani di Saribudolok. Proram Studi Magister Psikologi: Universitas Medan Area [Internet]. 2017 Aug [cited 2018 Oct 20].

[9] Goffin, A. Farmer's Mental Health: A Review of The Literature. ACC Policy Team [Internet]. 2014 Jan [cited 2018 Oct 22].

[10] Badan Pusat Statistik. Analisis Kebijakan Pertanian Indonesia. Implementasi dan Dampak Terhadap Kesejahteraan Petani Dari Perspektif Sensus Pertanian 2013. Jakarta. Badan Pusat Statistik [Internet]. 2014 [cited 2019 Feb 14].

[11] Robbins, S. P., \& Timothy, A. J. Perilaku Organisasi Edisi 12. Jakarta. Salemba Empat. 2008.

[12] Angelie, L. Peranan Gender pada Rumah Tangga Petani di Desa Sunten Jaya Kecamatan Lembang Kabupaten Bandung Barat. Fakultas Ekologi Manusia: Institut Pertanian Bogor [Internet]. 2014 Jan [cited 2019 Feb 15].

[13] Manyamsari, I., \& Mujiburrahmad. Karakteristik Petani dan Hubungannya dengan Kompetensi Petani Lahan Sempit (Kasus: Di Desa Sinar Sari Kecamatan Dramaga Kabupaten Bogor Jawa Barat) [Internet]. 2014 [cited 2019 Feb 22]: 15(2),58-74.

[14] Kurniasih, D., Sudarta, W., \& Parining, N. Hubungan antara Karakteristik Petani dengan Motivasinya dalam Membudidayakan Tanaman Tebu (Kasus Kelompok Tani Dewi Ratih 1, Desa Maospati, Kecamatan Maospati, Kabupaten 
Magetan). Fakultas Pertanian: Universitas Udayana [Internet]. 2017 Oct [cited 2019 Feb 24]:6(4),523-532.

[15] Azmi, M. R., Hasyim, H., \& Fauzia, L. Pengaruh Karakteristik Sosial Ekonomi Terhadap Sikap Petani dalam Penerapan Padi Sawah System of Rice Intensification (SRI) (Studi Kasus: Desa Pematang Setrak, Kecamatan Teluk Mengkudu, Kabupaten Serdang Bedagai). Fakultas Pertanian: Universitas Sumatera Utara [Internet]. 2014 [cited 2019 Feb 20].

[16] Dewi, I. N., Awang, S. A., Andayani, W., \& Suryanto, $P$. Karakteristik Petani dan Kontribusi Hutan Kemasyarakatan $(\mathrm{HKm})$ Terhadap Pendapatan Petani di Kulon Progo. Fakultas Kehutanan: Universitas Gadjah Mada [Internet]. 2018 Jun [cited 2019 Feb 25],8698.

[17] Febriastuti, H. N. Hubungan Dukungan Keluarga dengan Kejadian Insomnia pada Lansia di Dusun Krodan Maguwoharjo Depok Sleman Yogyakarta. Program Studi IImu Keperawatan: Sekolah Tinggi IImu Kesehatan 'Aisyiyah Yogyakarta [Internet]. 2015 Jun [cited 2019 Feb 24].

[18] Suprayitno, A. R., Sumardjo, Gani, D. S., \& Sugihen, B. G. Dukungan Lingkungan Sosial Budaya terhadap Kemampuan Petani dalam Pengelolaan Hutan Kemiri di Kabupaten Maros Provinsi Sulawesi Selatan. Fakultas Ekologi Manusia: Institut Pertanian Bogor [Internet]. 2012 [cited 2019 Feb 26]:8(1),114.

[19] Friedman, M.M., Bowden, V.R., \& Jones, E.G. Buku Ajar Keperawatan Keluarga Riset, Teori \& Praktik. Jakarta. ECG; 2013.

[20] Lambert, E. G., Minor, K. I., Wells, J. B., \& Hogan, N. L. Social Support's Relationship to Corretional Staff Job Stress, Job Involvement, Job Satisfaction, and Organizational Commitment. The Social Science Journal [Internet]. 2015 Oct [cited 2019 Feb 26]:1-11.

[21] Intani, A, C. Hubungan Beban Kerja dengan Stres pada Petani Lansia di Kelompok Tani Tembakau Kecamatan Sukowono Kabupaten Jember. Program Studi IImu Keperawatan: Universitas Jember [Internet]. 2013 Oct [cited 2019 Feb 27].

[22] Donsu, J. D. T. Psikologi Keperawatan. Yogyakarta: Pustaka Baru Press; 2017.

[23] Berk, O. S., Turetgen, I. O., \& Sun, E. Y. The Buffering Role of Social Support on the
Relationship between Job Stress and Intention to Leave. Journal of Business Research Turk [Internet]. 2017 [cited 2019 Feb 28]:9(3),213-230.

[24] Oktarina, R., Krisnatuti, D., \& Muflikhati, I. Sumber Stres, Strategi Koping dan Tingkat Stres pada Buruh Perempuan Berstatus Menikah dan Lajang. Fakultas Ekologi Manusia: Institut Pertanian Bogor [Internet]. 2015 Sep [cited 2019 Feb 28]:8(3),133- 141.

[25] Susanto, T., Purwandari, R. \& Wuryaningsih, W. E. Model Kesehatan Keselamatan Kerja Berbasis Agricultural Nursing: Studi Analisis Masalah Kesehatan Petani. Program Studi IImu Keperawatan: Universitas Jember [Internet]. 2016 Apr [cited 2019 Feb 28]:11(1),45-50.

[26] Favero, E., \& Sarriera, J. C. Disaster Perception,Self-efficacy, and Social Support: Impact of Drought on Farmers in South Brazil.International Journal of Applied Psyhology [Internet]. 2012 [cited 2019 Feb 28]:2(5), 126-136. 